\title{
Tuberculosis screening and active tuberculosis among HIV-infected persons in a Canadian tertiary care centre
}

\author{
Paul Brassard MD MSc FRCPC ${ }^{1,2}$, Travis Salway Hottes MSc ${ }^{2}$, \\ Richard G Lalonde MD FRCPC ${ }^{3}$, Marina B Klein MD MSc FRCPC ${ }^{2,3}$
}

P Brassard, TS Hottes, RG Lalonde, MB Klein. Tuberculosis screening and active tuberculosis among HIV-infected persons in a Canadian tertiary care centre. Can J Infect Dis Med Microbiol 2009;20(2):51-57.

RATIONALE: HIV infection increases the risk of reactivation of latent tuberculosis (TB). The present study evaluates how latent TB is detected and treated to determine the effectiveness of screening in HIV-infected patients with diverse risk profiles.

METHOD: A retrospective medical record database review (1988 to 2007) was conducted at a tertiary care HIV clinic. The proportion of patients receiving tuberculin skin tests (TSTs) and the rate of active TB at each stage of screening and prevention were estimated. Predictors of receiving a TST at baseline, testing positive by TST and developing active TB were evaluated.

RESULTS: In the present study, 2123 patients were observed for a total of 9412 person-years. Four hundred seventy-six (22.4\%) patients were tested by TST within 90 days of first clinic visit. Having a first clinic visit during the highly active antiretroviral therapy era (OR 3.64; 95\% CI 2.66 to 4.99), country of birth (ORs: Africa 3.11, Asia 2.79, Haiti 3.14, and Latin America and the Caribbean 2.38), time between HIV diagnosis and first visit (OR per one-year change 0.97; 95\% CI 0.94 to 0.99 ) and previous antiretroviral exposure (OR 0.61; $95 \% \mathrm{CI}$ 0.45 to 0.81 ) were independent predictors of receiving a TST at baseline. Of the 17 patients who developed active TB during follow-up, nine $(53 \%)$ had no documented TSTs at baseline or during follow-up. Forty-one per cent of all TB patients and $56 \%$ of TB patients who were not screened were born in Canada.

CONCLUSION: The administration of TSTs to newly diagnosed HIV patients was inconsistent and differential according to country of birth, among other factors, resulting in missed opportunities for TB prevention.

Key Words: HIV; Prevention; Risk profile; Screening; Tuberculosis

\section{Le dépistage de la tuberculose et la tuberculose active chez les personnes infectées par le VIH d'un centre de soins tertiaires canadien}

JUSTIFICATION : L'infection par le VIH accroît le risque de réactivation d'une tuberculose (TB) latente. La présente étude évalue comment déceler et traiter une TB latente pour déterminer l'efficacité du dépistage chez les patients infectés par le VIH ayant des profils de risque variés.

MÉTHODOLOGIE : Les auteurs ont procédé à l'analyse rétrospective d'une base de données de dossiers médicaux (de 1988 à 2007) dans la clinique du VIH d'un centre de soins tertiaires. Ils ont estimé la proportion de patients subissant un test de sensibilité cutané à la tuberculine (TST) et le taux de TB active à chaque phase de dépistage et de prévention. Ils ont évalué les prédicteurs de subir un TST aux premières visites, d'obtenir un résultat positif au TST et de présenter une TB active.

RÉSULTATS : Dans la présente étude, 2123 patients ont été observés pendant un total de 9412 personnes-année. Quatre cent soixante-seize $(22,4 \%)$ patients ont subi un TST dans les 90 jours suivant leur première visite à la clinique. Une première visite pendant la période d'antivirothérapie hautement active (RRR 3,64; 95 \% IC 2,66 à 4,99), le pays d'origine (RRR : Afrique 3,11, Asie 2,79, Haïti 3,14 et Amérique latine et Antilles 2,38), le délai entre le diagnostic de VIH et la première visite (RRR par changement au bout d'un an 0,97; $95 \%$ IC 0,94 à 0,99) et l'exposition antérieure à un antirétroviral (RRR 0,$61 ; 95 \%$ IC 0,45 à 0,81 ) étaient des prédicteurs indépendants d'administration d'un TST aux premières visites. Des 17 patients qui ont développé une TB active pendant le suivi, neuf (53\%) n'avaient pas subi de TST documenté aux premières visites ou pendant le suivi. Quarante et un pour cent de tous les patients atteints de TB et $56 \%$ de ceux qui n'avaient pas subi de dépistage étaient nés au Canada.

CONCLUSION : L'administration du TST aux patients infectés par le VIH nouvellement diagnostiqués n'était pas constante, et le différentiel selon le pays d'origine, entre autres facteurs, s'associait à des occasions ratées de prévention de la TB.
Simultaneous infection with HIV and tuberculosis (TB) act $\checkmark$ synergistically to complicate patient management and threaten public health (1). Patients infected with HIV have a markedly elevated risk for developing active TB, and active TB has deleterious effects on the course of HIV infection (2,3). In North America, this coinfection is of particular concern in urban settings with high rates of immigration (4). With the advent of highly active antiretroviral therapy (HAART), overall mortality and AIDS-related morbidity have dramatically improved among HIV-infected patients (5). In spite of these improvements, TB remains a major opportunistic infection in the post-HAART era (6-8).
The United States Centers for Disease Control and Prevention issued recommendations (9) as early as 1989 for the detection of TB among HIV-infected patients. Similar recommendations were issued subsequently in Canada (the Canadian Tuberculosis Standards [10]). Although the details of these guidelines differ somewhat, they both essentially recommend that all HIV-infected individuals undergo TB screening using tuberculin skin tests (TSTs), with a cut-off of $5 \mathrm{~mm}$ induration, which is considered to represent a positive test.

Several studies $(11-15)$ have demonstrated that clinician adherence to these recommendations has been remarkably low at HIV clinics in Europe and the United States. An analysis of

\footnotetext{
${ }^{1}$ Department of Medicine, Division of Clinical Epidemiology, Royal Victoria Hospital, McGill University Health Center; ${ }^{2}$ Department of

Epidemiology, Biostatistics, and Occupational Health, McGill University; ${ }^{3}$ Department of Medicine, Divisions of Infectious

Diseases/Immunodeficiency, Royal Victoria Hospital, McGill University Health Center, Montreal, Quebec

Correspondence: Dr Paul Brassard, Division of Clinical Epidemiology, McGill University Health Center, 687 Pine Avenue West R4-29,

Montreal, Quebec H3A 1A1. Telephone 514-843-1564, fax 514-843-1493, e-mail paul.brassard@mcgill.ca

Received for publication September 11, 2008. Accepted November 13, 2008
} 


\section{TABLE 1}

Baseline characteristics of cohort $(n=2123)$

\section{Age* $^{*}$}

Sex (male), n (\%)

Region of birth, $\mathrm{n}(\%)$

Canada
Africa
Haiti

Latin America and Caribbean (not Haiti)

Europe and diaspora (not Canada)

North Africa and Middle East

Asia

Unknown

Primary HIV risk factor, n (\%)

MSM

HIV endemic region

IDU

At-risk heterosexual

MSM/IDU

Blood transfusion

Mother-to-child transmission

First visit during HAART era (after 1996), n (\%)

On ARVs at baseline, $\mathrm{n}(\%)$

History of ADIs, $n$ (\%)

CD4 count*, cells/mL

HIV RNA*, $\log _{10}$ copies/mL

Time since HIV diagnosis*, years

Number of clinical visits per year*

HIV RNA was measured by Chiron branched-chain DNA testing, version 3.0. *Data are mean (range). ADI AIDS-defining illness; ARVs Antiretrovirals; HAART Highly active antiretroviral therapy; IDU Injection drug user; MSM Men who have sex with men

data from the Swiss cohort study (11), in particular, has highlighted the need for improvements in TB screening among HIV-infected patients. No similar study, however, has been conducted in an urban centre such as Montreal, Quebec, which has experienced rapidly increasing rates of immigration from countries where TB is endemic. Furthermore, the reasons for low-screening rates remain unclear; the assessment of patient characteristics in relation to testing patterns within a single clinic can provide clues to help understand the phenomenon. The present study, therefore, sought to evaluate how latent TB infection was detected and treated at a specialized immunodeficiency clinic in Montreal for the past 20 years.

\section{PATIENTS AND METHODS}

\section{Patients}

The immunodeficiency clinic at the Montreal Chest Institute (MCI; Montreal, Quebec) is a university-based clinic serving HIV-infected adults. Most patients are referred to the clinic by other health care providers in the city. In addition, the majority of individuals found to be HIV-positive during immigration health examinations in Montreal are referred to the program for medical care (Sylvain D, personal communication). Once referred, they receive most of their subsequent care at the clinic. A computerized database on all patients has been maintained since 1989, into which clinical, laboratory and prescription information have been prospectively entered.

\section{TST practices}

Throughout the study, no specific guidelines were followed uniformly in the clinic except for the general recommendation that the initial investigation of a new patient should include screening for TB. Screening at the clinic requires that a physician provide a written referral for a TST, which the patient brings to the clinic nurses who are trained in the administration and interpretation of the test. Purified protein derivative material is available at the clinic free of charge. A past history of bacille Calmette-Guérin vaccination was not considered when determining whether a TST was positive.

\section{Study design}

A retrospective cohort study was conducted using the clinical database. Patients were included if they were HIV-seropositive and had attended the clinic at least twice between July 12, 1988, and October 1, 2006. Patients were followed until April 1, 2007, to ensure a minimum of six months of follow-up, or censored at time of incident TB, death or six months after date of last visit if lost to follow-up. The study was approved by the research ethics board of the MCI. Patients were excluded if they had a history of active TB or were diagnosed with active TB within two weeks of their first visit.

\section{Variable definitions}

Demographic, testing, clinical and treatment data were extracted from the database. The primary variable of interest was receiving the TST within 90 days of first clinic visit (baseline). A 90-day window was chosen because the guidelines recommend that all patients receive a TST when HIV infection is first recognized $(10,16)$. Patients who received a TST but did not have their TST read were classified as untested. Additional variables of interest were testing TST-positive at baseline (a minimum induration of $5 \mathrm{~mm}$ ) and developing active TB during follow-up. To determine the completeness of TST reporting in the database, hospital charts were reviewed for a random sample of 90 patients who had no documented TSTs in the database, as well as for all cases of active TB. Active TB cases were identified from the clinical database (by diagnosis and/or the prescription of specific medications for the treatment of Mycobacterium tuberculosis) and were confirmed by chart review. The following baseline prognostic clinical factors were considered in analysis: age, sex, birth country, primary HIV risk factor, calendar year, duration of HIV diagnosis, CD4-positive (CD4+) T cell count, baseline HIV RNA, previous antiretroviral (ARV) exposure and history of AIDS-defining illnesses. Birth country was regrouped by geographical region as shown in Table 1. Haiti was grouped separately because of the large number of Haitian-born patients living in Montreal who are coinfected with HIV and TB (17).

\section{Statistical analysis}

Descriptive statistics were used to estimate rates of active TB at each stage of screening and prevention (ie, those who received the TST, who tested TST-positive, who initiated latent TB treatment and who completed latent $\mathrm{TB}$ treatment) and to characterize cases of TB. The rates of all outcomes were estimated by dividing the number of patients at each stage by the number of person-years at risk (from first clinic visit until censoring). Means were compared by two-sided Student's $t$ test for independent samples, and proportions and rates were compared by $\chi^{2}$ test, where appropriate (18). 


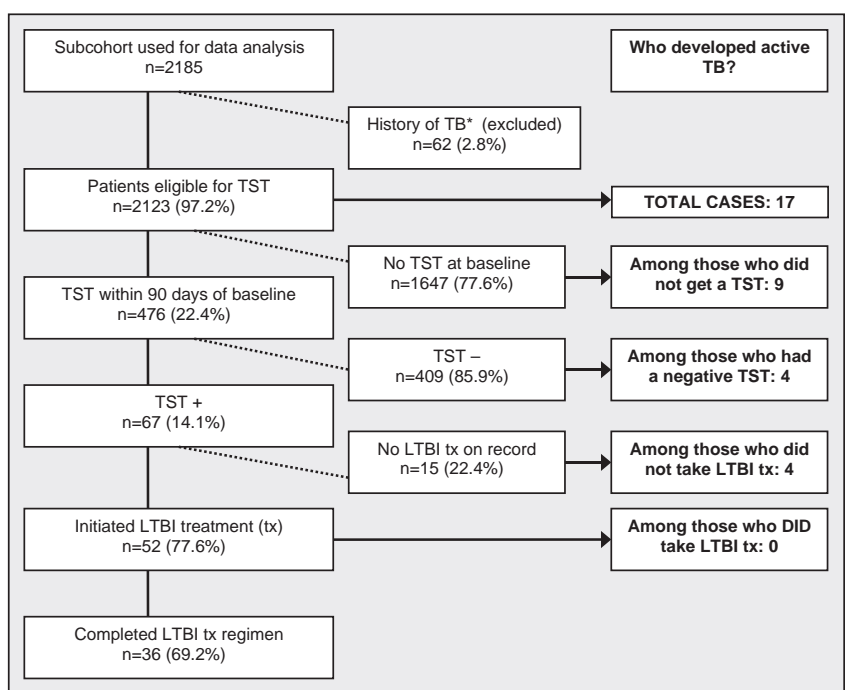

Figure 1) Stages of tuberculosis (TB) preventive measures and distribution of active TB cases. *The history of TB includes those who were diagnosed with TB within two weeks of first clinic visit. LTBI Latent tuberculosis infection; TST Tuberculin skin test

Multivariate logistic regression was used to identify independent predictors of the three dependent variables. Variables known a priori to be of clinical importance were included in all models (ie, age and CD4+ $\mathrm{T}$ cell count). Baseline CD4+ T cell count, viral load and time since HIV diagnosis had high proportions of missing values, which were estimated before multivariate modelling using the Multivariate Imputation by Chained Equations (MICE) program (19). Due to collinearity, region of birth and primary HIV risk factor were not included in the same multivariate model. Adjusted ORs for other variables were calculated using the model with the region of birth. Statistical analyses were performed using $\mathrm{R}$ version 2.4.1 (20). All multivariate models were checked for goodness of fit using a $\chi^{2}$ test (21).

\section{Patient characteristics}

\section{RESULTS}

In total, 2185 patients met the inclusion criteria, and 62 patients had a history of active TB or were diagnosed with active TB within two weeks of their first visit. These patients were, therefore, ineligible for a TST and for incident TB, and were excluded from analyses. The remaining 2123 patients were followed for a median of 3.1 years (9412 person-years). Summary characteristics of included patients are presented in Table 1.

\section{Proportion of patients screened}

TSTs were administered within 90 days of first visit for $476(22.4 \%)$ patients. Of those tested, $14.1 \%$ had a positive result. A flow chart illustrating the proportion of patients at each stage of screening and preventive treatment is shown in Figure 1. These proportions were found to vary by region of birth. Similar proportions of patients from Canada and Europe received TSTs at baseline (15.3\% and $15.7 \%$, respectively). By comparison, patients from Africa, Asia, Haiti, Latin America and the Caribbean, and North Africa and the Middle East were more likely to be TST tested $(46.9 \%, 41.2 \%, 37.0 \%, 35.5 \%$ and
TABLE 2

Comparison of perceived low- and high-risk region groups 'Low-risk' country 'High-risk' country of birth $(n=1521) \quad$ of birth $(n=599) \quad P$

\begin{tabular}{lrrr}
\hline Baseline characteristics & & & \\
Mean age, years & 39.13 & 36.22 & $<0.001$ \\
Sex (male) & 90.90 & 58.90 & $<0.001$ \\
Mean time since HIV & 4.57 & 1.68 & $<0.001$ \\
$\quad$ diagnosis, years & & & \\
Mean CD4 count, cells/mL & 273.10 & 261.4 & 0.35 \\
First visit post-HAART & 55.80 & 81.0 & $<0.001$ \\
$\quad$ era, \% & & & \\
History of ADIs, \% & 25.9 & 23.4 & 0.25 \\
On ARVs at baseline, \% & 28.0 & 24.2 & 0.09
\end{tabular}

Percentages of preventive measures by stage

\begin{tabular}{lccc} 
TST at baseline & $15.3(233 / 1521)$ & $40.4(242 / 599)$ & $<0.001$ \\
TST-positive & $4.3(10 / 233)$ & $22.7(55 / 242)$ & $<0.001$ \\
Initiated LTBI treatment & $80.0(8 / 10)$ & $92.7(51 / 55)$ & 0.49 \\
Completed LTBI & $100.0(8 / 8)$ & $90.2(46 / 51)$ & 0.81 \\
treatment & & & \\
Incidence rates of TB by each stage of screening/prevention & \\
All patients, excluding & 1.01 cases/ & 4.04 cases/ & 0.002 \\
those with history of TB & 1000 p-y & 1000 p-y & \\
Patients who received & 1.69 cases/ & 6.07 cases/ & 0.09 \\
TST at baseline & 1000 p-y & 1000 p-y & \\
Patients who did not & 0.87 cases/ & 2.69 cases/ & 0.08 \\
receive TST at & 1000 p-y & 1000 p-y & \\
baseline & & & \\
Patients who tested & 17.94 cases/ & 13.98 cases/ & 0.83 \\
TST-positive & 1000 p-y & 1000 p-y & \\
Patients who tested & 0.88 cases/ & 3.88 cases/ & 0.16 \\
TST-negative & 1000 p-y & 1000 p-y & \\
Patients who initiated & 0 cases/ & 0 cases/ & $N / D$ \\
(and completed) & 1000 p-y & 1000 p-y & \\
LTBI treatment & & & \\
Patients who did not & 60.46 cases/ & 183.45 cases/ & 0.31 \\
take LTBI treatment & 1000 p-y & 1000 p-y & \\
\hline
\end{tabular}

Student's test for independent samples used to compare means; $\chi^{2}$ test used to compare proportions and rates. ADI AIDS-defining illness; ARVs Antiretrovirals; HAART Highly active antiretroviral therapy; LTBI Latent tuberculosis (TB) infection; N/D Not determined; $p$-y Person-years; TST Tuberculin skin test

$28.6 \%$, respectively). Thus, for further comparisons of preventive measures, rates of active TB and general characteristics, the former regions were characterized as 'low risk' and the latter as 'high risk' (Table 2). This categorization correlates well with a grouping of countries by low- and high-incidence rates of TB according to World Health Organization data (22).

The proportion of patients screened for latent $\mathrm{TB}$ was also found to vary by time, increasing significantly from 1988 to 2006 ( $\chi^{2}$ test for trend; $\mathrm{P}<0.001$ ). This trend corresponded to a general increase in the proportion of new patients coming from 'high-risk' regions $\left(\chi^{2}\right.$ test for trend; $\left.\mathrm{P}<0.001\right)$, as shown in Figure 2 .

An additional 157 patients who did not receive a TST at baseline were tested at some time during clinical follow-up, yielding a total of $633(29.8 \%)$ patients screened for latent TB. These 157 patients were generally similar to those tested at baseline with regard to basic demographic and 


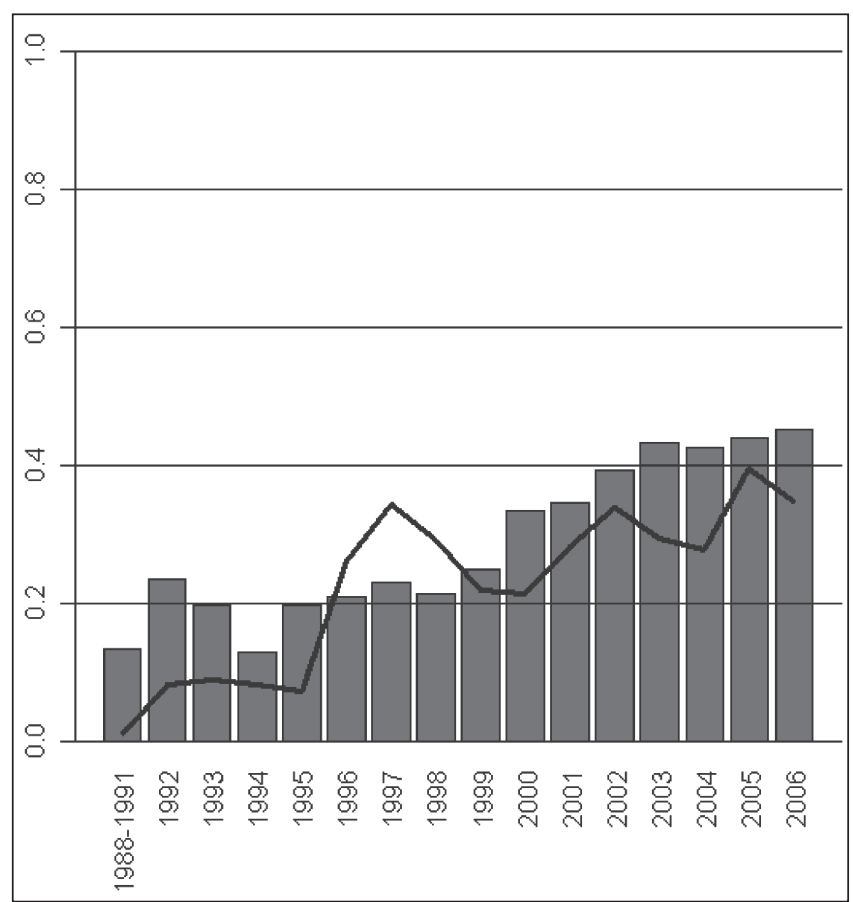

Figure 2) Proportion (\%) of new patients who received tuberculin skin tests at baseline (line) and were born in high-risk regions (bars), by year. $\chi^{2}$ test for trend in proportions getting a tuberculin skin test; $P<0.001$; $\chi^{2}$ test for trend in proportions of new patients born in high-risk regions; $P<0.001$

clinical characteristics; however, they had, on average, a significantly higher baseline CD4+ T cell count. Fortyseven of $411(11.4 \%)$ patients who tested negative at baseline received an additional TST during follow-up; none tested positive.

\section{Sensitivity analysis}

A review of hospital charts for a random sample of 90 (4.2\%) patients who had no TST recorded in the database revealed that the TSTs were in fact prescribed and read for $16(17.8 \%)$ patients. Assuming, based on this estimate, a misclassification rate of $\mathbf{1 7 . 8 \%}$ among those recorded as not having received a TST, a corrected estimate of proportion of patients TST screened at baseline would be $36.2 \%$ (95\% CI 30.1 to 43.9 ). Four of these 16 patients screened in the validation study tested positive. Characteristics of the misclassified TST patients were found to be similar to those of the overall cohort (data not shown).

\section{Determinants of TST}

Crude and adjusted ORs for variables associated with receiving a TST at baseline are shown in Table 3. Factors associated with having a TST were birth country and having a first clinic visit in the post-HAART era. CD4 cell count was not associated with having a TST. Individuals already on HIV treatment at baseline were less likely to be tested. Analyses were repeated using an outcome of TST at baseline or during follow-up, and results were found to be comparable with those when using only TST at baseline. Of the 157 individuals who received a TST during clinical follow-up, 20 (12.7\%) tested positive, and $18(90 \%)$ of these patients received treatment. None of the
TABLE 3

Determinants of receiving tuberculin skin test at baseline $(n=2123)$

\begin{tabular}{|c|c|c|}
\hline Variable & $\begin{array}{c}\text { Crude OR } \\
(95 \% \mathrm{Cl})\end{array}$ & $\begin{array}{l}\text { Adjusted OR } \\
(95 \% \mathrm{Cl})\end{array}$ \\
\hline \multicolumn{3}{|l|}{ Birth country (by region)* } \\
\hline Canada & Reference & Reference \\
\hline Africa & $4.89(3.65-6.55)$ & $3.11(2.18-4.45)$ \\
\hline Asia & $3.88(1.46-10.30)$ & $2.79(1.02-7.67)$ \\
\hline Europe and diaspora (not Canada) & $1.03(0.62-1.72)$ & $1.01(0.60-1.72)$ \\
\hline Haiti & $3.26(2.35-4.53)$ & $3.14(2.16-4.56)$ \\
\hline $\begin{array}{l}\text { Latin America and Caribbean } \\
\text { (not Haiti) }\end{array}$ & $3.05(2.05-4.53)$ & $2.38(1.56-3.61)$ \\
\hline North Africa and Middle East & $2.22(0.96-5.10)$ & $1.76(0.74-4.18)$ \\
\hline $\begin{array}{l}\text { First visit during post-HAART era } \\
\text { (after 1996) }\end{array}$ & $3.72(2.89-4.79)$ & $3.64(2.66-4.99)$ \\
\hline On ARVs at baseline & $0.58(0.45-0.74)$ & $0.61(0.45-0.81)$ \\
\hline $\begin{array}{l}\text { Time between HIV diagnosis and first } \\
\text { visit, years }\end{array}$ & $0.92(0.90-0.95)$ & $0.97(0.94-0.99)$ \\
\hline History of AIDS-defining illness & $0.56(0.42-0.73)$ & $0.79(0.57-1.08)$ \\
\hline Age at first visit, years & $0.99(0.98-1.00)$ & $1.00(0.99-1.01)$ \\
\hline Baseline CD4 count (per 50 cells/mL) & $1.00(0.98-1.02)$ & $1.01(0.96-1.02)$ \\
\hline $\begin{array}{l}\text { Baseline HIV RNA viral load } \\
\left.\text { ( } \log _{10} \text { copies } / \mathrm{mL}\right)\end{array}$ & $1.18(1.03-1.35)$ & $1.11(0.93-1.31)$ \\
\hline Sex (male) & $0.53(0.42-0.66)$ & $1.06(0.79-1.43)$ \\
\hline \multicolumn{3}{|l|}{ Primary HIV risk factor* } \\
\hline Men who have sex with men (MSM) & Reference & Reference \\
\hline Injection drug use (IDU) & $1.13(0.78-1.64)$ & $0.90(0.61-1.32)$ \\
\hline HIV endemic region & $3.06(2.38-3.92)$ & $2.14(1.54-2.96)$ \\
\hline Blood transfusion & $0.84(0.24-2.91)$ & $0.88(0.24-3.23)$ \\
\hline At-risk heterosexual & $1.40(0.97-2.02)$ & $1.02(0.67-1.55)$ \\
\hline Mother-to-child transmission & $1.28(0.26-6.21)$ & $1.57(0.30-8.28)$ \\
\hline MSM/IDU & $1.81(0.98-3.38)$ & $2.03(1.06-3.88)$ \\
\hline
\end{tabular}

patients who received a TST during follow-up developed active TB.

\section{Determinants of positive TST}

Among the 476 patients who were administered the TST at baseline, higher baseline CD4 count (OR 1.08; 95\% CI 1.01 to 1.16 per 50 cells), region of birth and primary HIV risk factor were associated with a positive TST in multivariate models. Patients from Africa (OR 8.00; 95\% CI 2.97 to 21.56) and Haiti (OR 4.65; 95\% CI 1.78 to 12.18 ) were significantly more likely to be TST positive than those born in Canada. There also appeared to be an increased risk of positive TST among patients from Asia and Latin America; however, the results were not statistically significant due to lack of power. The receipt of ARVs at baseline was not associated with a positive TST (adjusted OR 0.60, 95\% CI 0.22 to 1.62 ).

\section{Incidence of TB}

Seventeen patients developed active TB during 9412 personyears of follow-up (crude incidence rate of 1.81 cases per 1000 person-years). Nine (53\%) of these cases occurred among patients who were not screened at baseline or ever in follow-up (Figure 1), resulting in an incidence rate among the 
unscreened of 1.24 cases per 1000 person-years. Eight TB cases occurred among those who were screened (incidence rate 3.69 cases per 1000 person-years). Review of hospital charts confirmed diagnoses for all 17 patients with active TB the majority of which were pulmonary TB. There were five cases of extrapulmonary TB (one each of miliary, meningitis, spinal, enteritis and disseminated disease presenting with cutaneous lesions). All extrapulmonary cases had been TST tested and two of the five were TST-positive, but none received latent TB infection (LTBI) treatment.

\section{Characteristics of TB cases}

Compared with the entire cohort, the $17 \mathrm{~TB}$ patients were significantly younger at first visit (34 versus 38 years of age; $\mathrm{P}=0.01$ ), had shorter time periods between HIV diagnosis and first visit (1.79 versus 3.72 years, $\mathrm{P}=0.004)$, and were less likely to be male $(47.1 \%$ versus $79.5 \%, \mathrm{P}=0.003)$. They were also somewhat less likely to be born in Canada or have a primary HIV risk factor of 'men who have sex with men' (MSM). Three patients $(17.6 \%)$ were taking HAART at the time of TB diagnosis. The mean baseline CD4 count for these three patients was 275 cells/mL compared with 272 cells/mL for the entire cohort. Only three were receiving HAART (three others were on treatment interruptions for various reasons).

Among the nine patients who developed TB and were not TST screened, five (55.6\%) were born in Canada, five $(55.6 \%)$ were male and three $(33.3 \%)$ were MSM. By comparison, of eight patients who developed TB and were TST screened, two (25.0\%) were born in Canada, three $(37.5 \%)$ were male and one $(12.5 \%)$ was MSM. Four of the eight cases who were screened at baseline tested positive.

\section{Use of preventive treatment}

LTBI treatment is free in Quebec and is self-administered. Among the 65 patients who tested positive at baseline, 59 (90.8\%) initiated LTBI therapy; 54 (91.5\%) of these patients took isoniazid, and five $(8.5 \%)$ took isoniazid initially and then switched to rifampin because of the following side effects: gastrointestinal, drug-induced lupus, myalgia, headache and elevated liver function tests. Fifty-four (91.5\%) of 59 patients completed the recommended LTBI treatment regimen (nine months). The mean duration of treatment for those who did not complete the regimen was 97 days. There was no significant difference in proportions initiating LTBI treatment between patients coming from low-risk regions and patients coming from high-risk regions.

None of the patients who initiated LTBI treatment developed TB during follow-up. By comparison, four cases of TB occurred among the six TST-positive patients who did not take preventive treatment (crude incidence rate of 122 cases per 1000 person-years). Eighteen patients received LTBI treatment in spite of never having a positive TST; most of these patients were either immigrants from a high-risk country or had contact with a case of active TB.

\section{DISCUSSION}

To our knowledge, the present study is the first to study TST practice among HIV-infected persons in Canada. We found a differential approach to TST screening based on risk factors and numerous missed opportunities to prevent active TB. Despite recommendations that all HIV-positive patients be screened for latent TB shortly after diagnosis, as many as 70\% of patients failed to receive TSTs. The majority of TB cases within this cohort (nine of 17 ) occurred among patients who were not screened, resulting in an incidence rate 25 times the Canadian national rate in 2003 (23).

Receiving a TST is a multistep process that involves obtaining a prescription from a provider, actually receiving the intradermal tuberculin injection and returning $48 \mathrm{~h}$ to $72 \mathrm{~h}$ later for a reading. Thus, there are several opportunities for both the patient and the provider to fail to complete screening. Factors identified as determinants of receiving a baseline TST give some indication of how patients may have been selectively screened. Patients who had a greater delay between HIV diagnosis and first clinic visit, and those who were taking ARVs at baseline were less likely to receive a TST. It is possible that these patients were presumed to have already received preventive services and other care elsewhere. Region of birth and primary HIV risk factor (particularly emigrating from an HIV endemic region) were also independently related to receiving a TST at baseline. This raises questions about clinicians' preferential focus on particular groups perceived to be at higher risk for an opportunistic infection. At least one other study (24) has found that screening for sexually transmitted infections among HIV-positive patients varied by transmission risk factor and racial groups.

By assuming that patients originating from high-risk regions are in greater need of TB screening than Canadian-born patients or MSM, providers may be missing an opportunity to detect a large proportion of the TB cases that develop within the clinic's population. Although this assumption is well founded (patients from high-risk countries developed active $\mathrm{TB}$ at a rate four times that of patients born in Canada or Europe), the effects are detrimental: $41 \%$ of all the TB cases and $56 \%$ of the TB cases who were not screened were born in Canada - a clear indication that attention should be given to groups perceived to be at low risk. While relative cost-effectiveness of targeted versus universal screening strategies has been debated, HIV-infected persons have been identified as a targeted group; it is not recommended that they undergo further triaging by attributes such as country of birth or transmission risk factor - an injunction supported by our findings $(25,26)$.

We did not observe that a higher CD4 cell count was associated with the rate of TST testing, suggesting that clinicians were not selectively choosing to avoid testing individuals who may be anergic due to advanced immunodeficiency. However, because higher CD4 cell counts were associated with TSTpositivity among those screened, as has been previously reported (11), offering retesting after CD4 cell recovery following HIV therapy could represent an important strategy to reduce the number of incident TB cases. We found little evidence, however, that clinicians had retested patients (only $12 \%$ initially TST-negative were retested).

Of all the stages that presented opportunities for preventing cases of active TB, initiating LTBI treatment proved to be the most crucial. The incidence rate of TB among the TST-positive patients who failed to initiate LTBI treatment was 122 cases per 1000 person-years. This finding reinforces the importance of clinician and patient adherence to recommendations for isoniazid prophylaxis among TST-positive patients (27). It is noteworthy that while proportions of patients who screened and tested positive for LTBI varied by region of birth, once 
diagnosed, there were no significant differences in the clinical management of LTBI between these two groups. Chart review revealed that many patients failed to receive LTBI treatment because of potential drug interactions with HAART. Only three patients did not receive LTBI treatment because they failed to return to the clinic for follow-up visits and/or failed to comply with treatment regimens.

Our study offered a unique examination of factors associated with TST screening in a large study population with a high number of foreign-born patients, universal access to care and long duration of follow-up that permitted time-trend analysis. The results of our study parallel those of other studies that have examined TB screening among patients infected with HIV. The absence of ARV treatment $(11,15)$, female sex (15) and foreign birth (14) have been reported as determinants of receiving a TST in other cohorts. The independent predictors of positive TSTs in our study (CD4 count, country of birth and HIV transmission of risk factor) have similarly been identified as predictors (11).

The overall proportion of patients TST screened in the present study was low compared with estimates from other studies, which range from $54 \%$ to $69 \%$ (11-13). The TST screening proportion was also lower than the proportion of patients screened at the clinic at baseline for other infections such as syphilis (40\%), toxoplasmosis (41\%) and cytomegalovirus (40\%) (data not shown). TB screening differs from these other tests because it requires a second visit for the results to be read. Failure to return to the clinic may, in part, explain the lower completed screening rates observed. Based on the chart review, $9 \%$ of individuals without a documented TST result had received a TST but failed to return to the clinic for a reading. Ultimately, the use of a reliable blood test to detect latent TB may help to address this drawback of the TST. The results of the current study were presented to the clinic staff with the aim of improving TST testing rate in the clinic population.

Sensitivity analysis revealed under-reporting of TST in the electronic database used. However, characteristics of those misclassified were similar to the remainder of the cohort; thus, it is reasonable to assume that the misclassification was nondifferential and has not affected the validity of other results presented here.

\section{REFERENCES}

1. Friedland GH, Churchyard GJ, Nardell E. Tuberculosis and HIV coinfection: Current state of knowledge and research priorities. J Infect Dis 2007;196:S1-S3.

2. Selwyn PA, Hartel D, Lewis VA, et al. A prospective study of the risk of tuberculosis among intravenous drug users with human immunodeficiency virus infection. N Engl J Med 1989;320:545-50.

3. Havlir DV, Barnes PF. Tuberculosis in patients with human immunodeficiency virus infection. N Engl J Med 1999;340:367-73.

4. Haase I, Olson S, Behr MA, et al. Use of geographic and genotyping tools to characterise tuberculosis transmission in Montréal. Int J Tuberc Lung Dis 2007;11:632-8.

5. Palella FJ Jr, Baker RK, Moorman AC, et al. Mortality in the highly active antiretroviral therapy era: changing causes of death and disease in the HIV outpatient study. J Acquir Immune Defic Syndr 2006:43:27-34.

6. Hanna DB, Gupta LS, Jones LE, Thompson DM, Kellerman SE, Sackoff JE. AIDS-defining opportunistic illnesses in the HAART era in New York City. AIDS Care 2007;19:264-72.

7. Dore GJ, Li Y, McDonald A, Ree H, Kaldor JM. Impact of highly active antiretroviral therapy on individual AIDS-defining illness incidence and survival in Australia. J Acquir Immune Defic Syndr 2002;29:388-95.

8. Guenther T, Geduld J, Archibald CP. Tuberculosis among AIDS cases in Canada from 1994 to 1999: Analysis of data from the
We did not collect information on other factors that may be related to decisions to administer TSTs (eg, TB risk factors such as housing status, incarceration and other medical risk factors).

Finally, although we cannot be certain that all cases of active TB that occurred during follow-up were identified, given the nature and severity of the disease and the specific nature of TB treatment regimens, we believe that the vast majority of cases were captured in the database. The MCI is a primary centre for the treatment of TB in Montreal - 37\% of all TB cases in Montreal were seen at the MCI and affiliated hospitals in the last five years; therefore, it is unlikely that cases were diagnosed and treated elsewhere without the knowledge of the MCI HIV team. An underestimation of the number of incident TB cases would only enforce our conclusions that low rates of TST screening represent a missed opportunity for active TB prevention among HIV-infected persons.

Our findings support the recommendations of the Centers for Disease Control and Prevention, the Canadian Thoracic Society and the American Thoracic Society to screen all patients infected with HIV on diagnosis $(26,28,29)$. Clinicians should be advised of the important number of cases of TB occurring among HIV-infected patients, both Canadian-born and foreign-born $(17,22)$, and should be encouraged to screen all patients regardless of risk profile.

ACKNOWLEDGEMENTS: The authors thank the patients of the immunodeficiency service at the Montreal Chest Institute and their physicians - Drs James Allan, Norbert Gilmore, Roger Leblanc, John MacLeod, Martin Potter, Pierre René and JeanPierre Routy - without whom this study would not have been possible. They extend a special thank you to Tanya Murphy and Jordan Gagnon for initial analysis of this data set.

FUNDING: The present study was funded by the Réseau FRSQSIDA et maladies infectieuses. Dr Paul Brassard is supported by a new investigator career award from the Canadian Institutes for Health Research. Dr Marina Klein is supported by a ChercheurBoursier career award from les Fonds de la Recherche en Santé du Québec.

Canadian HIV/AIDS case reporting surveillance system. In: Abstracts of the 10th Annual Canadian Conference on HIV/AIDS Research. Canada: Can J Infect Dis, 2001.

9. Centers for Disease Control and Prevention. Tuberculosis and human immunodeficiency virus infection: Recommendations of the Advisory Committee for the Elimination of Tuberculosis (ACET). MMWR Morb Mortal Wkly Rep 1989;38:236-8,43-50.

10. Public Health Agency of Canada. Canadian Tuberculosis Standards. $<$ http://www.phac-aspc.gc.ca/tbpc-latb/pubs/pdf/tbstand07_e.pdf>. (Version current at December 1, 2008).

11. Elzi L, Schlegel M, Weber R, et al. Reducing tuberculosis incidence by tuberculin skin testing, preventive treatment, and antiretroviral therapy in an area of low tuberculosis transmission. Clin Infect Dis 2007;44:94-102.

12. Lee LM, Lobato MN, Buskin SE, Morse A, Costa OS. Low adherence to guidelines for preventing TB among persons with newly diagnosed HIV infection, United States. Int J Tuberc Lung Dis 2006;10:209-14.

13. Sackoff JE, Torian LV, Frieden TR, Brudney KF, Menzies IB. Purified protein derivative testing and tuberculosis preventive therapy for HIV-infected patients in New York City. AIDS 1998;12:2017-23.

14. Schulte JM, Bryan P, Dodds S, Potter M, Onorato IM, O'Sullivan MJ. Tuberculosis skin testing among HIV-infected pregnant women in Miami, 1995 to 1996. J Perinatol 2002;22:159-62. 
15. Welch KJ, Morse A. Improving tuberculin skin testing in HIV-infected individuals. Am J Respir Crit Care Med 2002;165:1452.

16. Kaplan JE, Masur H, Holmes KK. Guidelines for preventing opportunistic infections among HIV-infected persons - 2002. Recommendations of the U.S. Public Health Service and the Infectious Diseases Society of America. MMWR Morb Mortal Wkly Rep 2002;51:1-52.

17. Brassard P, Remis RS. Incidence of tuberculosis among reported AIDS cases in Quebec from 1979 to 1996. CMAJ 1999;160:1838-42.

18. Sahai H, Khurshid A. Statistics in epidemiology: Methods, techniques, and applications. CRC Press; 1996.

19. van Buuren S, Oudshoorn K. Multivariate imputation by chained equations. < http://www.multiple-imputation.com> (Version current at December 1, 2008).

20. R Development Core Team. R: A Language and Environment for Statistical Computing. Vienna: R Foundation for Statistical Computing, 2006.

21. Hosmer D, Lemeshow S. Applied Logistic Regression, 2nd edn. Wiley-Interscience Publication, 2000.

22. World Health Organization. Global tuberculosis control: Surveillance, planning, financing. < http://www.who.int/tb/publications/global_report/ en/> (Version current at December 1, 2008).
23. Public Health Agency of Canada. Tuberculosis in Canada. $<$ http://www.phac-aspc.gc.ca/publicat/2007/tbcan03/pdf/tbcan03e.pdf $>$ (Version current at December 1, 2008).

24. Kahle E, Zhang Q, Golden M, Goldbaum G, Buskin S. Trends in evaluation for sexually transmitted infections among HIV-infected people, King County, Washington. Sex Transm Dis 2007;34:940-6.

25. Mohle-Boetani JC, Miller B, Halpern M, et al. School-based screening for tuberculous infection. A cost-benefit analysis. JAMA 1995;274:613-9.

26. Centers for Disease Control and Prevention. Targeted tuberculin testing and treatment of latent tuberculosis infection. American Thoracic Society. MMWR Morb Mortal Wkly Rep 2000;49:1-51.

27. Schwartzman K, Menzies D. Tuberculosis screening of immigrants to low-prevalence countries. A cost-effectiveness analysis. Am J Respir Crit Care Med 2000;161:780-9.

28. Centers for Disease Control and Prevention. Anergy skin testing and tuberculosis [corrected] preventive therapy for HIV-infected persons: Revised recommendations. MMWR Morb Mortal Wkly Rep 1997;46:1-10.

29. Canadian Tuberculosis Committee. Recommendations for the screening and prevention of tuberculosis in patients with HIV and the screening for HIV in tuberculosis patients and their contacts. Can Commun Dis Rep 2002;28:1-6. 


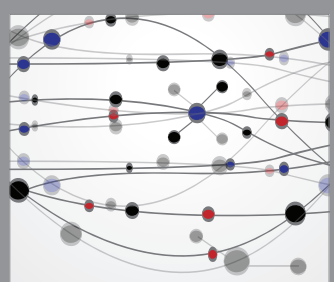

The Scientific World Journal
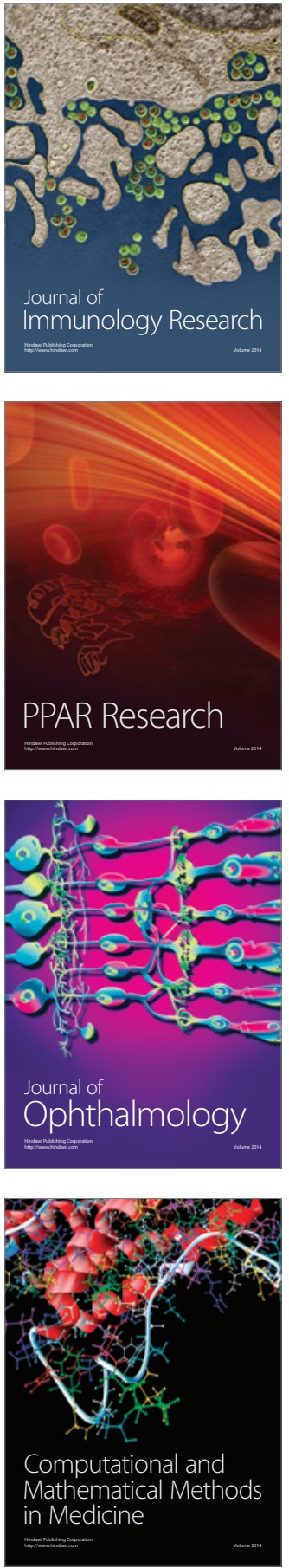

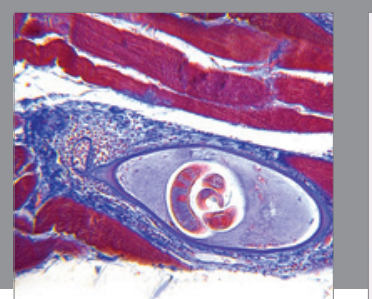

Gastroenterology Research and Practice

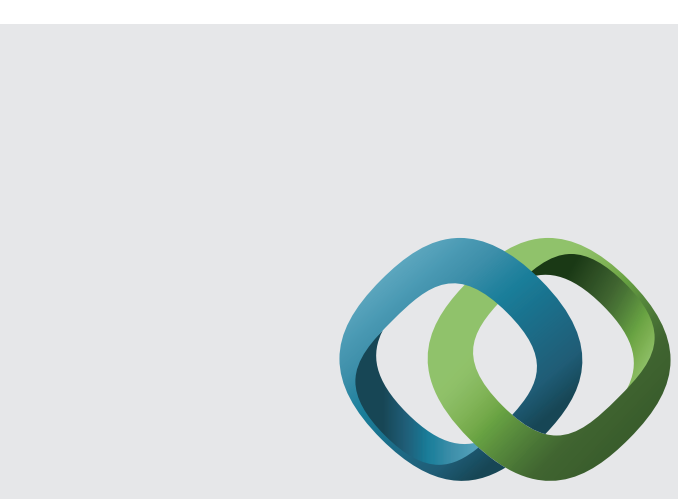

\section{Hindawi}

Submit your manuscripts at

http://www.hindawi.com
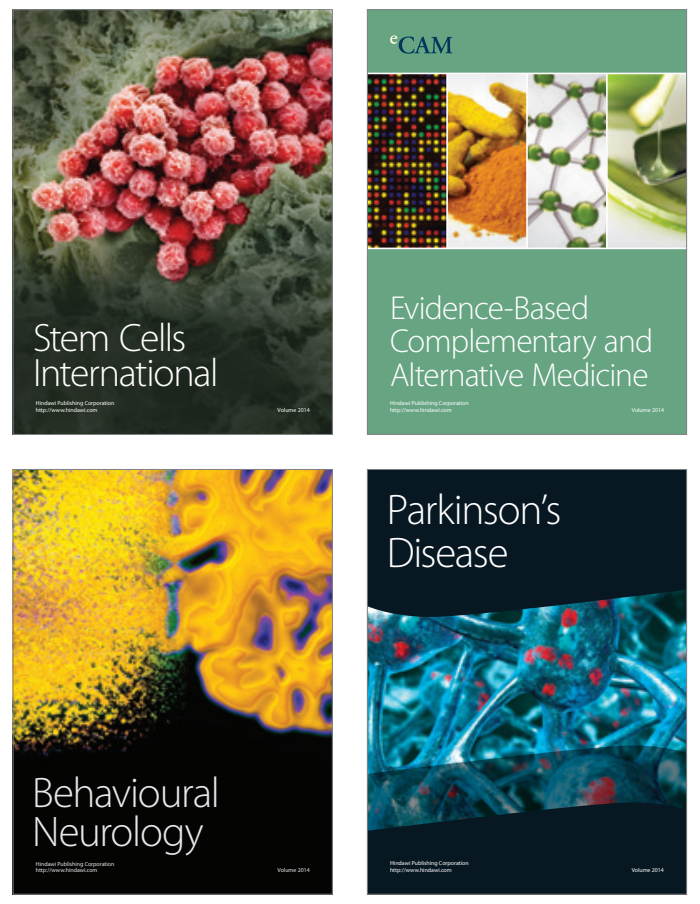
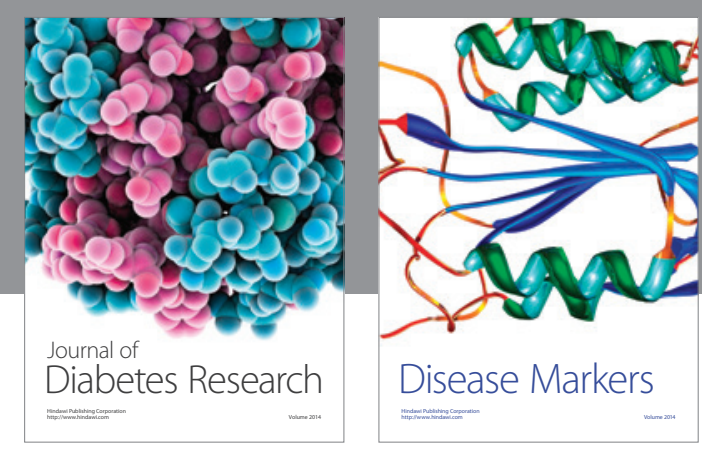

Disease Markers
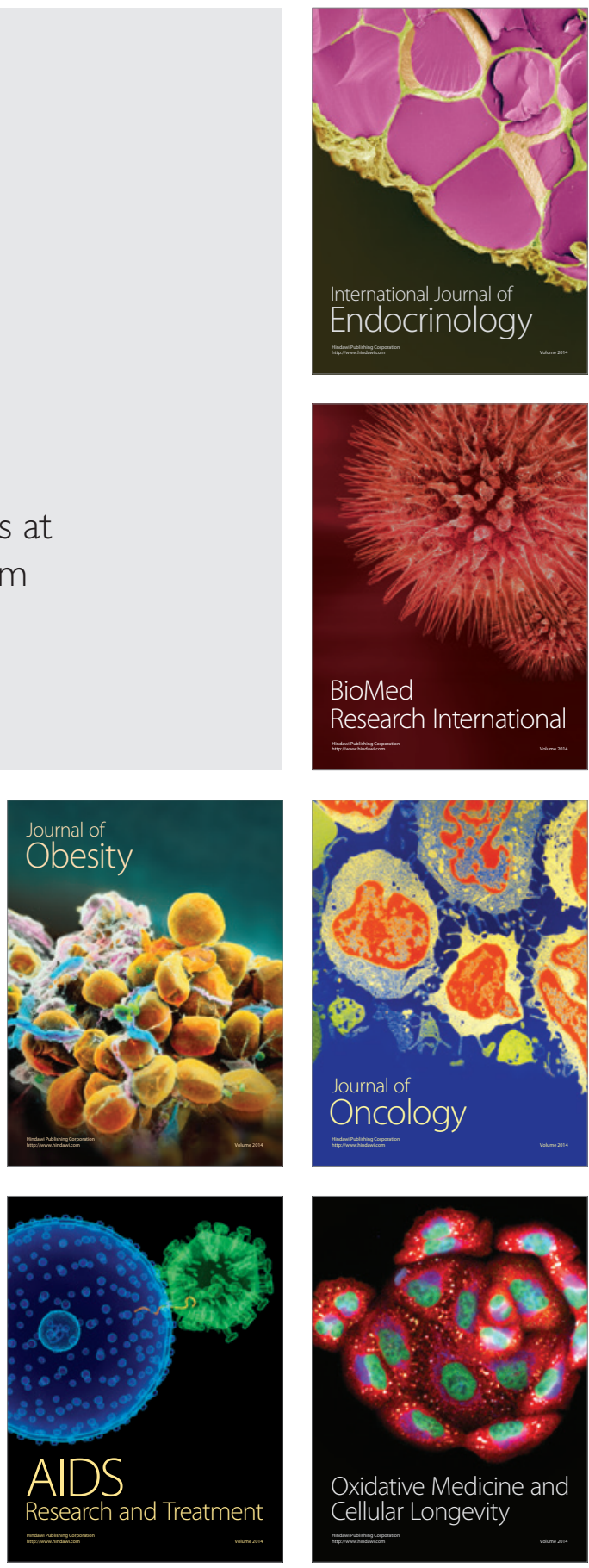